\title{
P-84
}

\section{A Validated Reverse Phase HPLC for Determination of Hydroxychavicol and Chavibetol in Piper Betle Extracts with Different Extraction Times and Locations}

\author{
Nurul Najwa Mohamad, Abdalrahim F.A. Aisha and Zhari Ismail ${ }^{*}$ \\ Department of Pharmaceutical Chemistry, School of Pharmaceutical Sciences, Universiti Sains Malaysia, 11800 \\ Minden, Pulau Pinang, Malaysia; E-mail: zhari@usm.my
}

Piper betle L., (Piperaceae) has been extensively used in traditional herbal remedies in India, Malaysia, Thailand and many other countries. Hydroxychavicol and chavibetol (isomer of eugenol) are the major marker compounds present in aqueous (PBA) and ethanol (PBE) of Piper betle extracts. The plant was reported to have various bioactivities such as antimicrobial, antibacterial, antifungal, antioxidant and anti-inflammatory. The objective of this study is to develop a HPLC method for quantification of hydroxychavicol and chavibetol in PBA and PBE from 2 locations prepared at 4 extraction times (1, 4, 8 and 24h). This analytical method showed linearity within the concentration range of $0.78-100 \mu \mathrm{g} / \mathrm{ml}\left(R^{2}=0.9987\right)$. The within-day and between-day precision indicated the relative standard deviation of retention time and peak area was $<0.3 \%$ and $<0.7 \%$, respectively. The percentage recovery of marker compounds at 3 concentrations was in the range $92.8-100.3 \%$. The limit of detection and quantification were in the range $0.03-0.06 \mu \mathrm{g} / \mathrm{ml}$ and $0.05-0.52 \mu \mathrm{g} / \mathrm{ml}$, respectively. Hydroxychavicol and chavibetol in PBA and PBE extracts was in the range $7.22-34.24 \%$ and $4.48-16.26 \%(\mathrm{w} / \mathrm{w})$, respectively. In the aqueous extracts, the highest percentage of hydroxychavicol was achieved at $24 \mathrm{~h}$ extraction time, whereas and chavibetol was not detected. On the other hand, hydroxychavicol and chavibetol were detected in ethanol extracts at all extraction periods with the highest concentration obtained at $24 \mathrm{~h}$ and $8 \mathrm{~h}$ extraction time. The method is linear, reproducible and cost effective for standardization of betel leaves.

Keywords: Piper betle, RP-HPLC, hydroxychavicol and chavibetol. 